\title{
Anorexia: o traço da obstinação na clínica psicanalítica
}

\author{
Isabel Fortes
}

Veremos como o traço da "obstinação" na anorexia mental reflete elementos fundamentais para a compreensão dessa patologia. A recusa, na anorexia, possui a função de reação ativa frente a um outro intrusivo. A negação é compreendida a partir de duas vias: como sustentação do desejo próprio ou como um modo de aniquilação do desejo. No entanto, estas duas vias podem ser pensadas não como contradição, mas como uma fecunda aporia. Do mesmo modo, o tema da "obstinação" é de suma importância para a clínica em geral, conduzindo a uma análise da negação como uma forma possível de relação com o desejo.

Palavras-chave: Anorexia, recusa, desejo, negação 
A contestação não é o esforço do pensamento para negar existências ou valores, é o gesto que reconduz cada um deles aos seus limites, e por aí ao Limite no qual se cumpre a decisão ontológica: contestar é ir até o núcleo vazio no qual o ser atinge seu limite e no qual o limite define o ser.

(Blanchot)

Chama bastante a atenção o modo como a recusa de alimento na anorexia se dá sob a forma de uma obstinação. O "não querer comer" nesta condição clínica concerne à atitude desafiante na relação com o outro, que se expressa por meio de tenacidade irredutível.

Pela negação do ato alimentar, a anoréxica opera uma manobra de separação do outro, buscando desvencilhar-se do estado de dependência em que se encontra, à procura de uma espécie de proteção contra o domínio invasivo do outro. Nestes casos, somente o recurso à negação radical, levada a cabo de maneira implacável, pode proporcionar defesa contra a onipotência materna. Ao excesso de invasão responde-se com equivalente intensidade de resistência.

Outra chave de leitura apresenta-se como fundamental para a compreensão desse traço. A obstinação não subentende somente uma posição desafiante ante o outro, mas é também elemento revelador de o quanto o sujeito em questão encontra-se profundamente amarrado ao ideal, encontrando-se aí a serviço do cumprimento de regras impostas por um superego tirânico que exige que se alcance o ideal a qualquer custo.

No presente artigo, propomos desenvolver o traço da obstinação a partir destes dois eixos de análise, demonstrando como o ato de negar pode expressar uma afirmação do desejo, manifestando uma resistência ativa do sujeito, mas pode ser também a aniquilação do desejo, quando está a serviço do objeto ideal.

Vejamos, primeiramente, de que maneira a obstinação nos ajuda na análise da problemática da anorexia. Em seguida, investigaremos como esse elemento é de suma relevância para a clínica em geral, ao expressar uma importante forma de relação com o desejo.

No artigo "Da anorexia histérica", de 1873, onde é pela primeira vez apresentado o termo "anorexia histérica", Charles Lasègue indica o traço da obstinação como sendo característico das anoréxicas, associando a recusa do alimento a uma "indolência mesclada de uma ponta de causticidade" (p. 168). As anoréxicas, segundo o autor, são indóceis e bastante tenazes no projeto de abster-se 
de comida. $\mathrm{O}$ autor adverte aos médicos para não tratarem a teimosia como sendo coisa passageira ou fácil de lidar, desconhecendo seu real perigo, pois isso acarretaria aumento do risco de vida que essas jovens correm:

Ai do médico que, por desconhecer o perigo, trata essa obstinação como fantasia sem importância, como que passageira, e espera vencê-la por meio de remédios, de conselhos amigáveis, ou pelo recurso ainda mais falho da intimidação! Com as histéricas, não há como consertar um erro médico inicial. (...) Elas não têm perdão e, quando consideram que as hostilidades começaram, sentem-se no direito de continuá-las com uma tenacidade implacável. (p. 161)

Lasègue dá uma recomendação sobre o manejo transferencial na anorexia, ao propor que de nada adianta nestes casos que se insista para que a paciente coma. A insistência - e entendemos que a advertência vale para a clínica psicanalítica de modo geral - só aumentará a resistência da paciente, pois “o excesso de insistência evoca um excesso de resistência" (p. 164). São pacientes que não fazem qualquer concessão, sendo bem difícil encontrar "o melhor meio para dobrar a teimosia das histéricas" (loc. cit.).

Ao percorrermos a literatura psicanalítica sobre o tema, vemos que o traço da obstinação, como característico dessa síndrome, foi trabalhado por inúmeros autores que sobre ela se debruçaram.

Bruch, em Golden Cage: The enigma of Anorexia Nervosa (1978), assinala que o absolutismo da negação tem nesse quadro a função de busca de "autonomia" e de "poder", elementos que define como sinais patognomônicos da doença. A autonegação relaciona-se aqui à busca por superioridade.

Ellen West, paciente tratada por Binswanger, ficou conhecida pelo fato de o psiquiatra ter publicado, em 1944, com descrição bastante detalhada, $O$ caso de Ellen West. Estudo antropológico-clínico. A paciente, pertencente à família abastada, era profundamente marcada por um ideal que nunca abandonou: melhorar as condições das massas. Trata-se de grande ideal que nunca desiste de alcançar, e para o qual dedica sua vida e seu trabalho. Ellen West entrega-se de forma obstinada a seu projeto; mesmo nos períodos mais críticos da doença ela nunca deixou de dizer que queria fazer algo grandioso e alcançar seus objetivos, demonstrando fidelidade permanente ao objeto ideal, conforme relatado por Binswanger (1944): "Não consigo respirar nessa atmosfera de falsidade e covardia; desejo fazer algo grandioso e necessito aproximar-me um pouco mais de meu ideal - do meu orgulhoso ideal" (p. 10). Esse modo de relação com o objeto sinaliza uma forte presença do superego, que interpela e pressiona o ego, fazendo-o sentir-se sempre aquém do ideal.

Com efeito, o relato de Binswanger aponta a todo o momento a presença dos traços de perfeccionismo e obstinação: 
Era boa aluna, gostava de ir à escola; era muito ambiciosa, podia chorar durante horas quando não tirava o primeiro lugar nas matérias de que mais gostava e não queria faltar às aulas nem por ordem médica, receosa de não acompanhar a classe ou de perder alguma coisa importante. (p. 3)

Por outro lado, a teimosia foi uma característica que sempre a acompanhou, não admitindo jamais ser contrariada:

Ellen foi uma criança bastante vivaz, porém teimosa e irascível. Com frequência, resistia durante horas a uma ordem dos pais e, ainda assim, não a cumpria. Certa vez mostraram-lhe um ninho de pássaro; com assertividade, declarou que não se tratava de um ninho de pássaro e de modo algum foi possível dissuadi-la disso. (p. 3)

Assim, desde pequena, todos ao seu redor ficavam intimidados com o tom de certeza e o grau de assertividade da menina. Essa marca continuou a acompanhá-la ao longo de sua vida: "Tudo o que aborrece Ellen é aquilo que impede seu eu desafiante, violento; tudo o que limita, ameaça e contraria sua sensação de domínio" (Magtaz e Berlinck, 2008, p. 3).

Há também o célebre exemplo da escritora Simone Weill, que mostrou, desde a infância, ser uma menina caprichosa e indomável, sendo também muito inteligente e movida por grande ideal a ser atingido (p. 5).

Bidaud (1998) interpreta da seguinte forma o que denomina a "bela obstinação" da anoréxica:

A "bela obstinação" da anoréxica, já destacada por Lasègue, essa "irritante" perversão do querer, é um desafio soberano dirigido ao outro, de quem o sujeito quer demonstrar que não depende. O "não tenho fome", proferido placidamente, é uma bofetada lançada ao outro. Trata-se de mostrar, de estar ali diante do olhar assustado ou escandalizado. Ser, sem ter de se justificar, é o privilégio dos deuses. A anoréxica se afirma, assim, contra qualquer troca: ela não quer convencer. Como os deuses, (...) ela se apresenta como não se tendo originado da necessidade comum, nem sujeito nem objeto de demanda alguma. Tentando estabelecer seu domínio do objeto da necessidade, ela se desfaz de uma relação com o outro, percebida como alienante e despedaçadora (p. 25, grifo nosso).

Dessa maneira, o ato de "não comer" surge, como dissemos mais acima, como dispositivo para se separar, "como o único meio de escapar ao domínio do olhar materno" (Jeammet, 1999, p. 3). Trata-se de um sujeito que estaria totalmente submetido ao Outro, possuindo pouca margem de manobra para se separar: "Tudo se passa como se o ajuste conveniente sujeito-objeto não tivesse podido ser feito, deixando persistir uma dependência que priva o sujeito de si mesmo (Brusset, 1999, p. 55). Frente ao querer tão impositivo do Outro, o sujeito bus- 
ca o domínio do objeto da necessidade como modo de anteparo ao estado de dependência extrema.

A tentativa de se sobrepor ao registro da necessidade - agir como os deuses - é também assinalada por Assoun (1983), a partir da dimensão de um "puro querer", de um "domínio do querer" (p. 134) que na anorexia conduz à verdadeira ascese. A ascese do corpo só pode se realizar por meio de um "querer de ferro", operado à custa do desejo. Ocorre, então, desintrincação da fome e da sexualidade, sendo a fonte do emagrecimento do corpo o "curto-circuito" entre a sexualidade e a função nutritiva. O domínio do querer reduz o outro à condição de "objeto parcial" recusado ou de instrumento de um programa de controle. A certeza do querer absoluto constrói uma barragem ao desejo do Outro: "Pois este 'nada' ao qual reduz o seu desejo, ela o produz com a energia de um querer totalitário" (p. 136).

A demanda é assim invertida - nada mais querer dever à mãe, manifestando dessa forma a tentativa de romper com a dependência do outro. A questão da dependência do objeto materno tem lugar central na anorexia, que responde a isso por meio de formação reativa: "Eu nunca pedi nada a ninguém”, evidenciando um sujeito que, para escapar da dependência, bloqueou qualquer comércio com o outro:

É aí a missão que a anoréxica parece impor a si mesma, pagando-a diretamente à custa do próprio corpo: tornar possível - e isso ela o faz - fazer parar o trem do desejo em direção ao Outro e recolher a demanda, bloqueá-la sobre o corpo próprio (loc. cit.).

A negação é assim realizada por meio do corpo - um “corpo-querer" que fez o luto da demanda e do desejo, até a morte: "Corpo fálico, enfim - com o longo caminho de sofrimento e de privação que implica este resultado. Mas isso permite justamente não mais precisar... de nada" (Assoun, 1983, p. 136).

Pela via da recusa, busca-se desfazer a relação de dependência maciça com o outro. É neste sentido que podemos conceber a recusa a partir da dimensão de resistência.

Assim, se o querer obstinado consistiria em manobra para se separar do outro, o "não preciso de nada" obstaculiza a ordem do desejo. Neutralizar o desejo transformando-o em pura necessidade tem a função de libertar da dependência, mas acaba por enfraquecer a própria dimensão desejante.

Em “Un cas d'anorexie mentale”, Maud Mannoni assume ponto de vista diferente do de Assoun, ao propor que a negação do alimento indica uma tentativa de sustentação do desejo próprio, mostrando como, pela via da recusa, a paciente busca alguma afirmação de si. $O$ ato que diz "Eu não quero comida" subentende o "Eu quero" do desejo que busca um caminho para se fazer surgir: "A 
anorexia, neste contexto, não é exatamente uma 'doença', mas a única forma que o indivíduo encontra para nascer enquanto sujeito desejante, fora do desejo da mãe" (Mannoni, 1970).

Portanto, apresentamos acima duas vias possíveis de análise que se encontram presentes nos estudos acerca da anorexia mental. Por um lado, essa patologia é vista como forma de aniquilação de qualquer desejo. Por outro, trata-se de uma formação sintomática que tenta, pelo viés da negação, promover um modo de resistência e de possível afirmação do desejo próprio.

Mas como podemos, no exercício de nossa prática clínica, vislumbrar sinais que nos indiquem de qual das interpretações se trata? Entra aí em cena, a nosso ver, o desafio permanente para a sensibilidade do psicanalista. Para cada paciente em particular, trata-se de indagar se nos encontramos diante de uma força de resistência, de busca de afirmação, mesmo que frágil, do próprio desejo ou, ao contrário, de entrega de si mesmo ao nada mortífero que conduz o sujeito à desistência...

No entanto, é importante ressaltar que o tema da "obstinação" não se restringe exclusivamente à clínica da anoréxica, mas constitui um elemento importante na clínica psicanalítica em geral.

O desenvolvimento apresentado por Recalcati (1997), para a articulação das duas vias aparentemente opostas acerca da anorexia, permite trazermos elaborações pertinentes à função da negação de modo mais geral. O autor sinaliza que na obra lacaniana entreveem-se as duas vertentes supostamente antagônicas. Em Complexos familiares na formação do indivíduo (1984) a anorexia é descrita como um "desejo de larva", articulando duas dimensões - o desejo e a larva - que são contrárias pelo fato de, a princípio, não haver nada de parasitário no desejo. Como salienta Recalcati, o desejo consiste, por excelência, em ser "antilarva". Enquanto a larva se mostra inerte e passiva frente à tensão vital da existência, o desejo acontece totalmente associado à tensão inerente ao fato de estarmos vivos.

Desse modo, quando une o desejo à larva, a anoréxica já nos indica a direção para compreender sua posição, mostrando que aqui "o ser que absorve é também aquele que é absorvido" (p. 68). Por negar o desejo, a anorexia é vista como forma de atração pela morte, operando por meio do sintoma, a destruição da ordem desejante. A segunda definição lacaniana para a anorexia, exposta no artigo "A direção da cura e os princípios de seu poder" (1958), explicita a recusa como oposição à presença maciça do outro, uma forma que o sujeito encontra de salvaguardar o próprio desejo.

Portanto, a obra lacaniana desenvolve estas duas perspectivas sobre as quais nos debruçamos. Segundo Recalcati (2001), no artigo intitulado "Os dois 'nada' na anorexia", há nesta condição clínica duas maneiras de conceber o "nada". O primeiro "nada" é aquele que aponta para uma manobra de separação, visando 
reduzir a onipotência do Outro em impotência, como forma de descolar o sujeito de sua dependência alienante. Aqui, o nada é aquilo que consente em uma virada radical da relação de força: por meio do ponto-chave da recusa, do "não!" ao Outro, através da função do nada como objeto separador, o sujeito lança o Outro em uma espécie de impotência angustiante, conquistando assim uma posição de supremacia imaginária no confronto com o Outro (p. 28). O segundo "nada" é quando ocorre eclipse total da demanda, cuja consequência é a mortificação do desejo, como mencionamos mais acima.

O autor propõe que não é preciso optar necessariamente por uma ou outra interpretação, mas concebê-las conjuntamente, como fruto de uma "fecunda aporia" (p. 69). Assim, há o surgimento do desejo, mas este se manifesta como um "desejo frágil", pois consiste em um desejo que só consegue se expressar pela negação.

A noção de aporia pode ser transposta para pensar a negação na clínica psicanalítica em geral. No campo da filosofia, a figura da aporia é entendida quase sempre como uma proposição sem saída lógica, quando uma sentença parece contradizer-se a si mesma (Ferrater-Mora, 2000). Como na aporia não há contradição, e sim relação de forças entre dois polos logicamente opostos, a proposta de pensar a relação com o desejo, quando este se manifesta pela negação como uma aporia, permite dizer que as duas posições - o desejo e a negação - não são excludentes, mas podem coexistir como uma espécie de tensão vital (Recalcati, 1997, p. 69).

Podemos aproximar a ideia de "desejo frágil" da noção de "princípio de agonia" proposta por Pontalis (1988) no artigo "Não, duas vezes não". Se circunscrevermos o traço da "obstinação", como fazemos neste artigo, ao tema da negação na clínica psicanalítica, é possível concebê-la no quadro da resistência não como impedimento à análise, mas como força ativa. A noção de aporia nos ajuda nesta reflexão, pois remete ao fato de que a resistência condensa ao mesmo tempo desejo de análise e negação do processo de análise.

Sabemos que na teoria freudiana a resistência é fundamental para o manejo clínico, sendo somente a partir dela que o analista pode realizar o seu trabalho. Essa noção foi definida por Freud $(1905 ; 1923$; 1937) como a força que faz com que o paciente se apegue ao sofrimento e lute, muitas vezes, contra o próprio restabelecimento.

Pontalis (1988) propõe que o fato de se fixar no sofrimento, muitas vezes até obstaculizando qualquer possibilidade de melhora, não significa necessariamente que o paciente assim o faça porque prefere o sofrimento à melhora. Segundo o autor, não se trata exatamente de uma preferência, pois não nos encontramos aqui na dimensão do gozo, mas de uma condição vital, que é circunscrita mais à 
ordem do ser do que à ordem do gozo. Portanto, em certos casos clínicos, pode-se dizer que a resistência seria um modo de afirmação da própria existência.

A luta contra o restabelecimento - o "não!" à melhora - seria, portanto, uma reação afirmativa que derivaria da luta interna promovida pelo sujeito para não sucumbir ao Outro:

Podemos ouvir nisso, junto com o sentido usual de recusa da cura, um outro sentido, que imputaria à própria reação um efeito terapêutico: ideia de uma reação salutar no organismo, conforme ele volta a se assenhorear de si - isto é, luta por se desfazer da dominação do outro - e se afirmar em sua individualidade. (Pontalis, 1988, p. 65)

A negação, sob esta ótica, configura-se como força ativa, havendo uma afirmação presente no próprio ato de negar. Para não atender à expectativa do outro de que coma, a anoréxica diz não à comida, assim como o paciente resistente diz não à análise como forma de não atender à expectativa do outro de que melhore. Observa-se, então, o recurso à negação como modo de resistência que lhe permite alguma brecha em relação ao próprio desejo: resistir para existir. O "não" aqui diz respeito a um exercício de potência, constituindo-se menos como uma representação, e mais como um ato ou uma descarga.

Pensar a negação como força ativa conduz a problematizar a própria ideia de reação. Esta última pode ser vista como ativa quando observamos que a reação é na verdade uma ação que se faz frente à outra ação. Trata-se de um re-agir e, portanto, de um agir (p. 61).

Quanto ao tema da reação, Pontalis nos remete à elaboração feita por Starobinski (2002) sobre o par ação-reação. Os polos deste último são muito mais estreitamente ligados do que os polos do par ação-paixão, que prevaleceu até o século XVII. Enquanto a paixão se define como um contrário lógico da ação, o par ação-reação se caracteriza por reciprocidade, simetria, interação sem mediação, pois os dois termos obedecem a mesma lógica. Desde que a ciência newtoniana estabeleceu que "a toda ação se opõe sempre uma reação igual", estes dois termos passaram a ter uma correspondência direta:

Nomes abstratos, substantivos derivados de verbos intransitivos, "ação e reação" são noções simples, simétricas, quase especulares, nas quais se concentra a imensa variedade de tudo o que age "enquanto age", de tudo o que reage, "enquanto reage". Ficamos felizes em encontrá-los quando estão emparelhados, porque opõem e conciliam. (p. 13)

Assim, o "re-agir" é resposta a um "agir" anterior, os dois formando uma parelha não de termos contrários, mas de um "par-compensado" que segue uma lógica em comum. Não é à toa que o termo "reação" apresenta forte ressonân- 
cia na obra freudiana, como, por exemplo, na formação reativa, na noção de abreação como uma reação adiada, ou ainda na definição da transferência concebida como um agieren.

Quando surge uma força reativa no processo psicanalítico, isso é sinal de que o analisando está ocupado em exercer uma força ativa sobre o analista como pessoa, operando-se então um enfraquecimento do trabalho do analista como intérprete, como suporte da transferência: "O analisando está, à parte as palavras que consegue dizer, inteiramente ocupado em exercer uma força ativa sobre - geralmente, contra - o analista como pessoa. Assim, encontramo-nos no registro do agir, mesmo que esse agir só seja veiculado por palavras" (p. 62).

Mas entrevê-se neste movimento reativo, ao mesmo tempo, o indício de que se está tocando em algo importante para o avanço da análise. Como lembra Pontalis, uma das regras áureas do método psicanalítico é compreender que a resistência anuncia a proximidade do material inconsciente.

O problema que se coloca aqui é quando a resistência é confundida com a defesa. Quando pensamos a reação como força ativa, aludimos especificamente ao movimento da resistência, e não ao da defesa. Enquanto aquela é pontual e suscitada pelo próprio movimento da análise, esta última diz respeito a características do funcionamento psíquico global do indivíduo, não sendo interpretável. A resistência encontra-se circunscrita ao processo a que estão submetidos, ao mesmo tempo, o paciente e o analista, aparecendo como obstáculo à análise, opondo-se à emergência de uma representação ou de um afeto, sendo, por isso, interpretável, quando a representação e o afeto podem ser nomeados pelo analista.

Assim, conceber a resistência como força ativa implica entender de outra forma a reação terapêutica negativa, retirando-se o aspecto deficitário com que esta é comumente vista. O "não" passa a ser entendido como elemento intrínseco ao processo analítico desses pacientes, não se constituindo em um movimento que impediria o seu desenrolar. Assim, deixa-se de considerar a negação como deficiência, anulação ou subtração, passando-se a vê-la como o único modo que o sujeito encontra para reassegurar e afirmar a própria existência: "A impotência é sempre a admissão de que há onipotência do outro (...). Frente a essa onipotência, a essa excitação permanente, a esse excesso de mãe dentro de si, só há uma resposta: a reação!" (p. 65).

No caso, não se trataria mais de inércia, mas de "uma força sofrida e exercida: o domínio do não" (p. 71).

Nesses seres onde a oposição tornou-se a própria razão de ser, o "ser não", como aponta Sztajnberg (1992), apresenta-se como a única alternativa possível ao "não ser", sendo só possível existir por meio da negação: "Renunciar a essa oposição implica um risco de morte como sujeito, equivalente a tombar em vala comum, anônima, onde não podem mais ser reconhecidos na sua diferença. Re- 
curso drástico de não ser condenado à condição de objeto do desejo alheio" (mimeo).

No entanto, é necessário ressaltar: dizer que há aí força ativa não retira da negação seu traço agonístico. O estado daqueles que se expressam pelo "não" é atravessado por um "princípio da agonia, regido pela lógica do desespero, para além do princípio do prazer" (Pontalis, 1988, p. 57). Este é um ponto que merece atenção, pois ao dizer que a negação é a única saída encontrada pelo sujeito como alternativa a sucumbir ao outro, estamos refletindo acerca de sujeitos nos quais se evidencia a escassez de recursos psíquicos. Encontramos na proposta de Pontalis uma ressonância possível com a solução encontrada por Recalcati para a aparente contradição das perspectivas acerca da anorexia. Se reconhecermos que a recusa anoréxica indica sustentação do desejo, admitimos tratar-se, para usarmos o termo de Pontalis, de desejo circunscrito ao princípio da agonia, ou seja, o único modo possível de desejar para aqueles que se encontram em total estado de desespero. A nosso ver, a ressonância entre os dois autores está no fato de tanto um como outro apresentarem uma resolução possível para a aparente contradição que pode haver em certos casos clínicos na relação do desejo com a negação. As perspectivas do "desejo frágil" e do "princípio de agonia" retiram da negação seu caráter exclusivo de "sem saída", propondo que mesmo quando impera o impulso negativo em uma análise pode-se, ainda assim, apostar na sustentação do desejo.

Concluindo, portanto, a análise da "obstinação" nos auxilia a compreender como a negação do desejo pode se apresentar como saída possível, embora precária, que o sujeito encontra para a sustentação do próprio desejo. A obstinação significa tenacidade, mas envolve também a teimosia. O obstinado é antes de tudo um birrento, aquele que busca a todo o custo contrapor-se ao outro como uma forma de afirmação de si. Ora, vimos como a anoréxica usa o recurso da obstinação para efetivar sua radical oposição ao outro. O absolutismo de sua recusa é testemunho da tentativa de separação de um outro invasivo. Ao destacarmos, neste artigo, este elemento tão frequente na clínica da anorexia mental - a obstinação - é para, a partir dele, mostrar quão complexas são na clínica psicanalítica as relações entre o desejo e a negação.

\section{Referências}

Assoun, P.-L. Freud et la femme. Paris: Calmann-Lévy, 1983. . Freud et Nietzsche. Paris: P.U.F., 1980.

BIDAud, É. Anorexia. Rio de Janeiro: Companhia de Freud, 1998. 
BinswANGER, L. (1944). O caso Ellen West. <http://www.fundamentalpsychopatology. org/app/index.php>. Acesso em: 30 maio 2010.

Bruch, H. The Golden Cage: the enigma of Anorexia Nervosa. Harvard: Harvard University Press, 1978.

BrusSET, B. Anorexia mental e bulimia do ponto de vista de sua gênese. In: URRIBARRI, R. (Org.). Anorexia e bulimia. São Paulo: Escuta, 1999.

Fernandes, M. H. Transtornos alimentares. São Paulo: Casa do Psicólogo, 2006.

FREUd, S. (1905). Três ensaios sobre a teoria da sexualidade. In: Edição Standard Brasileira das Obras Psicológicas Completas de Sigmund Freud. Rio de Janeiro: Imago, 1974-1976. v. VII, p. 135-237.

. (1913). A disposição à neurose obsessiva. In: Edição Standard Brasileira das Obras Psicológicas Completas de Sigmund Freud. Rio de Janeiro: Imago, 19741976. v. XII, p. 399-412.

. (1920). Além do princípio do prazer. In: Edição Standard Brasileira das Obras Psicológicas Completas de Sigmund Freud. Rio de Janeiro: Imago, 1974-1976. v. XVIII, p. 17-88.

. (1923). O ego e o id. In: Edição Standard Brasileira das Obras Psicológicas Completas de Sigmund Freud. Rio de Janeiro: Imago, 1974-1976. v. XIX, p. 13-86.

. (1937). Análise terminável e interminável. In: Edição Standard Brasileira das Obras Psicológicas Completas de Sigmund Freud. Rio de Janeiro: Imago, 1974-1976. v. XXIII, p. 247-288.

JEAMMET, P. Abordagem psicanalítica dos transtornos das condutas alimentares. In: Urribarri, R. (Org.). Anorexia e bulimia. São Paulo: Escuta, 1999.

LaCAN, J. (1984). Os complexos familiares na formação do indivíduo. Rio de Janeiro: Jorge Zahar, 1987.

. (1956-1957). O seminário. Livro 4. A relação de objeto. Rio de Janeiro: Jorge Zahar, 1995.

. (1958). La direction de la cure et les principes de son pouvoir. In: Écrits.

Paris: Seuil, 1966. p. 585-646.

Lasègue, C. (1873). Da anorexia histérica. Revista Latinoamericana de Psicopatologia Fundamental, São Paulo, v. I, n. 3, p. 158-171, set.1998.

Magtaz, A.C.; Berlinck, M.T. Reflexões sobre "O caso de Ellen West". Estudo Antropológico-clínico, de Binswanger. Revista Latinoamericana de Psicopatologia Fundamental, São Paulo, v. XI, n. 2, p. 232-238, jun.2008.

Mannoni, M. Un cas d'anorexie mentale. In: Le psychiatre, son "fou" et la psychanalyse. Paris: Seuil, 1970. 
Pereira, M.E.C. Apresentação a "Da anorexia histérica". Revista Latinoamericana de Psicopatologia Fundamental, São Paulo, v. I, n. 3, p. 155-157, set.1998.

Pontalis, J.-B. (1988). Não, duas vezes não. In: Perder de vista. Rio de Janeiro: Jorge Zahar, 1991.p. 54-73.

Recalcati, M. Os dois "nada" da anorexia. Correio - Revista da Escola Brasileira de Psicanálise, São Paulo, n. 32, p. 26-36, 2001.

. (1997). La última cena: anorexia e bulimia. Buenos Aires: Del Cifrado, 2007.

StARobinski, J. Ação e reação: vida e aventuras de um casal. Rio de Janeiro: Civilização Brasileira, 2002.

Sztajnberg, R. Nego, logo existo. Anais do Simpósio “Mais além da psicanálise”. Rio de Janeiro: SPCRJ, nov.1992.

\section{Resumos}

(Obstinacy in anorexia: the trait of obstinacy in psychoanalytic clinical practice)

Here we consider how "obstinacy" in mental anorexia reflects elements that are fundamental for an understanding of this pathology. In anorexia, refusal serves as an active reaction against intrusion by another. Denial can be understood in two ways: as a means of sustaining one's desire, or as a way to extinguish desire. But these two paths need not be seen as contradictory - they can be seen as fertile aporias. The theme of "obstinacy" is thus very important in clinical psychoanalysis, and allows an analysis of denial as a possible form of a patient's relationship with desire.

Key words: Anorexia, refusal, desire, denial

(Anorexie: le trait de l'obstination dans la psychanalyse)

Nous verrons que le trait de l' "obstination" dans l'anorexie mentale reflète des éléments fondamentaux pour la compréhension de cette pathologie. Dans l'anorexie, le refus joue le rôle de réaction active face à un autre intrus. La négation se comprend à partir de deux voies: en tant qu'entretien du désir propre ou comme une manière d'annihiler le désir. Cependant, ces deux voies peuvent être pensées non pas comme une contradiction, mais comme une aporie féconde. De même, le sujet de l' "obstination" a une très grande importance pour le tableau clinique en général, car il mène à une analyse de la négation comme un moyen possible de rapport avec le désir qui se manifeste dans le cadre clinique psychanalytique.

Mots clés: Anorexie, refus, désir, négation 
(Anorexia: trazo de la obstinación en la clínica psicoanalítica)

Veremos como el trazo de la 'obstinación' en la anorexia mental refleja elementos fundamentales para la comprensión de esa patología. El rechazo, en la anorexia, posee una función de reacción activa frente a un otro intruso. La negación es comprendida a partir de dos vías: como sostén del deseo propio o como un modo de aniquilación del deseo. Sin embargo, estas dos vías pueden ser pensadas no como contradicción, sino como una fecunda aporía. Del mismo modo, el tema de la 'obstinación 'es de suma importancia para la clínica en general, conduciendo a un análisis de la negación como una forma posible de relación con el deseo.

Palabras clave: Anorexia, rechazo, deseo, negación

Citação/Citation: ForTes, I. Anorexia: o traço da obstinação na clínica psicanalítica. Revista Latinoamericana de Psicopatologia Fundamental, São Paulo, v. 14, n. 1, p. 83-95, mar.2011

Editor do artigo/Editor: Prof. Dr. Manoel Tosta Berlinck

Recebido/Received: 22.11.2009 / 11.22.2009

Aceito/Accepted: 13.2.2010 / 2.13.2010

Copyright: () 2009 Associação Universitária de Pesquisa em Psicopatologia Fundamental/ University Association for Research in Fundamental Psychopathology. Este é um artigo de livre acesso, que permite uso irrestrito, distribuição e reprodução em qualquer meio, desde que o autor e a fonte sejam citados/This is an open-access article, which permits unrestricted use, distribution, and reproduction in any medium, provided the original author and source are credited.

Financiamento/Funding: A autora declara não ter sido financiados ou apoiados/The author declares that has no support or funding to report.

Conflito de interesses/Conflict of interest: A autora declara que não há conflito de interesses/The author declares that has no conflict of interest.

\section{ISABEL ForTES}

Psicanalista; professora Visitante do Programa de Pós-Graduação em Teoria Psicanalítica da Universidade Federal do Rio de Janeiro - UFRJ (Rio de Janeiro, RJ, Brasil); membro do Espaço Brasileiro de Estudos Psicanalíticos (Rio de Janeiro, RJ, Brasil).

Rua Paulo César de Andrade, 240/601 - Laranjeiras

22221-090 Rio de Janeiro, RJ, Brasil

e-mail: mariaisabelfortes@gmail.com 